\title{
Challenges of Education in a Postmodern Environment
}

\author{
Nataliya Chernyuk Favennec \\ Paris Descartes University Sorbonne, France
}

\begin{abstract}
The education system is in the midst of an adaptation crisis. The traditional approach fails to meet the needs of the younger generation, which grows increasingly resistant to outdated teaching methods. Empirical scientific data and research shows there are considerable benefits in utilizing an empathic pedagogical approach. Exposing students to an empathic learning environment allows for creativity, awakens motivation and renews a taste for learning; it can even reveal previously unrecognized potential. Requiring just personal initiative, any teacher can take this approach and reap the benefits. There is no need to await comprehensive changes from the education system itself. In order to be effective, the education system must be consistent with the society of his time. While society and attitudes have changed, the institution is not regenerated. One wonders about the impact of media, new technologies and social networks on youth attitudes. These factors would guide to the superficial, immediate, and virtual and engender a reflex of "zapping". They also induce a loss of the sense of reality, questioning the boundaries between the virtual and the real. Whereas the effectiveness of the education system is inextricably linked to its ability to stimulate the student's desire to learn, it is essential to seek mechanisms generating interest and involvement of the student.
\end{abstract}

\section{Introduction}

This research starts from the observation of an ongoing crisis of French educational institution based on the republican model. By the 1970s, the "conflictualists" sociologists have studied and denounced the mechanisms that make the school a factor of the continuation of social inequality. Previous governments have implemented numerous educational policies often at the expense of consistency and efficiency. The challenges of dealing with a massive system and efficiency of the school. There are indications of deterioration in the school climate as well as recurrent lower academic performance of students, as shown by surveys such as Program for International Student Assessment (PISA). French schools based on modern values at odds with the social environment and loss of efficiency.
We propose to conduct an analysis of the French schools in the light of the paradigm of postmodernity. French educational institution operates on a system of values inherited from the modern era, characterized by rationality and verticality, (i.e. transfer of knowledge from the top down) the individual is expected to conform to a model. These values, like traditional republican institutions are obsolete and no longer work. However, the postmodern era is characterized by the emergence of a topical horizontality (i.e. learning from your peers and your teacher), a new concept of interpersonal relationships and communication with each other. There is also a resurgence of archaic and sensitive values. These are phenomena characteristic of trends in postmodern societies, influencing attitudes and representations, particularly among young people. Remaining impervious to the new social environment, the Republican school institution is in discordance with the people in which is in charge of training, and thus, becomes inadequate and "unperformant."

Pedagogical transformation began in the 20th century, thanks to the contributions of psychology, including constructivism in the sense of a better mobilization of psychological functions of the individual. From the 1960s, the evolution of pedagogy in theory relies on the work of humanist psychologists who have improved the understanding of the mechanisms of motivation and highlighted the importance of concepts such as self-esteem. These concepts have contributed to educational changes, which have supported research on "process-product" and the reflective practices of teachers. However, it clearly appears that the contributions of psychology and the results of these studies are insufficiently integrated practice in the educational process in France.

The fact remains that educational change is incomplete as the school is not attuned to the social environment. The paradigm theories of Jung applied to education, focused on the archetypal nature of the teacher-student relationship. In addition, we further stress, convergence with theories of imagination. We intend to demonstrate that the proper implementation of an "archetypal" education, leveraging the sensitivity, intuition, empathy and the "resonance" is a powerful contributor to education. The goal is to seat the connection between student knowledge and enhancement of personal potential. The 
establishment of such an educational relationship is currently based on an individual approach of the teacher including their own self-analysis in order to improve the transfer of knowledge.

In conclusion, the incorporation of these concepts in the organization of the educational institution would require a thorough overhaul of the educational process, but also the recruitment and training of teachers.

\subsection{Discrepancy between school and post modernity}

The educational world is facing a new challenge. Postmodern thought focuses on living in the moment, and understand our individual desires. This leads to a stronger value of the ephemeral, and a culture more focused on human emotions. It goes against traditional values based on reason, ideologies and hope of better future.

These conditions are leading to the development of a youth culture that is diverse, tribal, progressive and based on new technologies instead of the values of older generations.

Compliance with academic standards was once a pawn of success, but now it no longer develops students to their full potential because they are neither stimulated nor motivated by it. In turn, this makes the school no longer accomplish their primary goal anymore to educate students and prepare them for life after school. Schools are no longer having as much of a role in student's social life anymore because of the diversity of the current student population. As a result an education system that does not meet the needs of a younger generation.

Any innovative idea must face the natural and social reluctance and precious time elapses before its relevance is needed at all. To be effective, the education system must be consistent with the society of his time. But while society and attitudes have changed, the institution is not regenerated. Institution is no longer resonating with the society. It strives to treat a form of visible discomfort without actually identify the real causes. "Education should not be reduced to technical rationality...It is because such forms of education do not address the whole child in all of his physical, emotional, political, cultural, and ethical complexity. The result is psychic "disorientation and fragmentation" in children, which will lead with tragic inevitability to the same things in a society whose citizens and leaders those children will one day be." [1]

One wonders about the impact of media and new technologies: mobile phone, Internet, games, social networks, on youth attitudes. These factors would guide to the superficial, immediate, and virtual and could engender a reflex of "zapping", an inability to sustainable attention and mental effort. It also can induce a loss of the sense of reality of same adolescents, questioning the boundaries between the virtual and the real. As noted by JeanPierre Goudailler, it is a really linguistic divide contributing to increase marginalisation of youth [2]. Dominique Baillet, which assimilates these language forms a sort of "against-culture". Through technology, music, cyber culture, young people have built a low permeability adult world. They also reflect the identification of tribal forms as highlighted by Michel Maffesoli, who recalls that "from an ethnological point of view the tribe, stricto sensu, was a way to fight together against the multiple forms of adversity..." [4]. Postmodern tribalism would not be foreign to a protective instinct from our origins.

\subsection{The need for harmony in the student- teacher relationship}

Our work claims that a harmonious relationship between student and faculty is a strong motivating factor for students in the learning proses.

A postmodern pedagogical approach favours teaching skills and transmission of knowledge in a fashion that allows student to choose how they interpret and apply what they are learning.

Regardless of the school programs, personality of the teacher plays an important role in the process of students' learning. Perrenoud called this 'informal knowledge' the "hidden curriculum" well known in Anglophone literature [5].

The personality of the teacher also determines the quality of his/her relationship with the student. A better education system would result from teachers who take this into account.

In this vision, Clifford Mayes suggest us the spiritual way of teaching, which requires that the teacher constantly work at developing her or his intuitive capacity - in how she or he relates to both her or his subject-matter and students.

"Teaching with the third eye, teaching with "wholesight" - it is fascinating how the symbol of the eye pervades the literature on intuitive teaching. Yet another variation on this theme comes from Don Juan, who talks, in his typically comic but ultimately serious way, of seeing, learning and teaching "crosseyed." Don Juan is instructing Castaneda about how to find his sitio or "location of power". In Buddhist meditation, the master will also sometimes talk about the importance of finding one's "seat". This is botn a physical and spiritual locale, the existentially and spatially centered point from which the student 
learns to see and respond to the flow of events with efficiency and compassion. But one cannot reason oneself in the direction of this spot. It takes intuition to find." [6]

For this purpose, we emphasize the importance of sensitivity and empathy in education, more and more noticed by psychologists and sociologists such as Carl Rogers, Boris Cyrulnik, René Barbier, JeanDaniel Rohart and many others, but whose educational institution ignores. However, the sharing of emotions, dialogue, and exchange are necessary for the peaceful resolution of differences and the transmission of knowledge.

Whereas the effectiveness of the education system is linked to its ability to stimulate the student's desire to learn, it is essential to seek mechanisms in order to generate interest and involvement of the student in learning. It is necessary to find new ways of understanding the student, a changing relationship with the teacher, a new report on education.

Michel Maffesoli believes that true knowledge is currently in the "gaps" in the unveiling of what is happening, what is offered to us in ordinary knowledge. It evokes the connection between "freedom of mind and strength of the sensible" [8].

Indeed, the sensitivity can be leveraged to create intense moments of education, by the matching of minds. It creates correspondence, "interstitial realities", timely occasions as the ancient Greeks called kairos. Pierre Bourdieu suggests that the sophists were accustomed to say what is important in learning it is the appropriate time or kairos [9]. These moments of symbiosis between teacher and student, these magical moments of communion are particularly conducive opportunities to the initiation and learning.

These moments of symbiosis, these favourable circumstances to learning can be leveraged, even caused, when the actors of education gain better control. These prospects are particularly promising as empirical experiments. It is important to underline that taking into account the sensitive pedagogy is able to generate positive interactions, to introduce harmony in the transmission of knowledge.

The efficiency of the education system depends on the effectiveness of each individual teacher. Everyone has the right to change its methods for creating more productive and motivating learning situations and thus helps to reveal the latent potential of students.

These educational experiences from personal initiatives of teachers remaining isolated, have only limited influence. Such an approach could, however, give its full potential by being concretely supported and coordinated by educational institution.

\section{The possibility of an archetypal approach to education}

We propose an archetypal approach to education. Jung describes archetypes as a psychic process of the collective unconscious which generates common representations, or primordial images in our unconscious mind.

Archetipal pedagogy could contribute to a better medium of communication to the education system. Unconscious wishes which are deeply inside each human beings have an important impact on motivation. This pedagogy could motivate students by connecting their inner desires to their education experience. The art is very important in this approach to education, which "are not taught for their own sake; they are taught because they allow a child to experience a subject on a level far deeper and richer than the intellectual, it is the archetypal level. And this can be true of any subject, even the most traditionally scientific." [10]

The search for optimal learning situations involves a process of adaptation to the ambient atmosphere in the classroom and the sensitivity of each student in order to maximize personal skills and moments conducive to receptivity.

Students are volunteers for new experiences. The teacher must ensure to maintain the curiosity, must be able to listen to, to generate interest or even passion for the subject.

It is also crucial in the microcosm of the class, create a climate of sharing and conviviality, more oriented toward teaching the values of sensitivity, empathy, trust and understanding of others. The pleasure of learning is consistent with the pleasure of "being together "mentioned by Maffesoli, which states that "the life of our society integrates more sensitive, more sensations in its overall structure." [11]

The learning process should provide the student pleasure, freedom of expression, incitement to creativity. Traditional teaching is very focused on standardized exercises. It lacks of flexibility, which is essential for everyone to express themselves according to their own way of being. We feel in each class latent wealth, inhibited by the rules and dogmas, abilities that are waiting to be revealed. There are students in an untapped potential. This potential if not detected and recovered, contrary to risk investing in the cons - productive forms. 
The freedom to think and create the desire to depart from the traditional norms sometimes can be seen as unsuitable by the traditional education system. However, it is strange to see that it is in these moments of freedom that the teacher can discover his own students and help to reveal unsuspected abilities in them. In these moments, it is found that normally shy or reserved students have the opportunity to build their self-confidence. These moments trigger the externalization of their talents. The ideas, suggestions, willingness and motivation arise then. The emotion and sensitivity are true catalysts of student motivation. It is the same for artistic activity, which is a way to assert themselves by exposing themselves to the outside eye, which causes the pupil fertile interactions and sense of self-esteem.

"Students must be allowed to "fail" in productive and supportive ways that draw upon the creative possibilities of dialectical tension in promoting deep and lasting moral and intellectual growth.(...)it is important for teachers to understand transferential psychodynamics both personally and archetypally in order for their interaction with students to be most appropriate and fruitful... education must be holistic, addressing the whole child in those many historical, cultural and political contexts within which the child develops psychospiritually." [12]

"...the idea of transference in teacher-student relationships is the single most important issue that psychoanalysis addresses for the educationist...The psychoanalytic pedagogues have vociferously claimed that the teacher, although not a therapist, can, if armed with a basic knowledge of the fundamental principles and practices of psycholoanalysis, teach in ways that are psychologically wise and sometimes even therapeutically efficacious." [13]

This education process requires that the teacher himself/herself adapt to be able to tune in with their students to create moments which allow students to realize their own hidden potential, which the Greeks refer to as "kairos".

The archetypal approach allows us to provide students the support necessary to experience enriching education that goes beyond the simple transmission of knowledge and prepares the student for the world. In recent years, the education system has lost sight of this objective. A reformation of the school system requires a reform of teacher training so that teachers acquire skills of adapting their teaching style so students can experience "kairos".

\section{Initiation, the other mode of socialization, revealing potential}

"All primitive groups and tribes that are in any way organized have their rites of initiation, often very highly developed, which play an extraordinarily important part in their social and religious life. Through these ceremonies boys are made men and girls women. The Kavirondos stigmatize those who do not submit to circumcision and excision as "animals." This shows that the initiation ceremonies are a magical means of leading man from the animal state. They are clearly transformation mysteries of the greatest significance. Very often the initiands are subjected to excruciating treatment, and at the same time the tribal mysteries are imparted to them, the laws and hierarchy of the tribe on the one hand, and on the other the cosmogonic and mythical doctrines. Initiations have survived among all cultures." [14]

Emile Durkheim saw education as an instrument of socialization. More than ever the postmodern individual is in search of personal fulfillment. Beyond culture, school should also - and most importantly - give each child a better understanding of himself and his potential. It should first of all be given the means to reveal their personal potential. Michel Maffesoli reminds us that: "When we look at human history, there are two forms of socialization..."educare" which means "pull " is demanding, requiring self-discipline (...) and it seems to me more to match the spirit of the times. And there's another way to socialize, it's initiation. I would say that it is education that is modern. The initiation was pre-modern and, perhaps, will be post-modern. The initiation, unlike education, do not assume that there is nothing in the mind of one who is in front of me, the listener. It is postulated that there is something and I'll walk, bring out the treasure, somehow, this person is in front of me, while education considers that there is a void that I must fill (...)." [15]

Postmodernity, as shown by Michel Maffesoli dedicated return archaisms. In "The re-enchantment of the world", he suggests "the return of the initiatory desire is an echo that of postmodernity." [16] It seems that the concept of education as conceived by Durkheim, who belongs to the socalled modern era, no longer fits completely with our postmodern time. The ancient concept of initiation could become a leitmotiv in socialization.

We should be engaged with the mood of the moment with the background noise of the world.

Speaking about that, the French sociologist Michel Maffesoli elaborates for us his analysis of postmodern society. From his point of view: “...the postmodern includes elements that were specific to 
pre-modernity, that is to say, it sees the resurgence of timeless characteristics, which are contemporaneously a new realization. Thus these archaic forms - of the tribe, the nomadic, or pleasure of being - which had been marginalized in the progressivism, rationalism and functionalism specific to modern times, found an undeniable presence in postmodern everyday life. Another specificity of this postmodern eon, this atmosphere of postmodern being, is seen precisely in the fact that, once beyond Comte's reductio ad unum, the plural tends to prevail. I have often said that the figure in both the esoteric and exoteric sense of modernity was the number one. The metaphor from this leads to monotheism, mono-deism or what Nietzsche called ironically monotonothéisme. In contrast to this, we now see - to use an image of Max Weber - a polytheism of values, showing that the individual is diffracted into plurality, that the nation-state is faced with the resurgence of diverse localisms, and that its institutions tend to fragment into infinite tribalism.

This is a mosaic construction which really captures postmodern sensibility..."

Michel Maffesoli proposed a definition of postmodernisme as: "The synergy between archaic phenomena and technological development" [17] [18]. The figure of the oxymoron characterizes the mood of the moment. That is to say:" Synergy, let us not forget, is more than simple addition, more than simple multiplication. It is, in its strict sense, a reduction of the forces in play. I would speak of a mutual fertilization of phenomena that had been previously separated. The French sociologist Edgar Morin correctly described complexity as a retroactive process. And it is certainly this process that is in play within postmodernism. Speaking metaphorically in order to illustrate this process, I recalled that, in contrast to the arrow of time with its progressive and reactionary directions, the figure that would best characterize postmodernity is that of the 'spiral'.(...)To put it simply, I put the tribe and the internet together. In order to describe a synergy like this one concerning both archaic and technological development..." [19]

We have undertaken a comprehensive review of the postmodern society in order to gain a full and complete picture of it. Michel Maffesoli provided us with a detailed analysis of the postmodern society at a nascent stage.

On the question of education, we observed a clear lag between schools and society as a whole. The educational institution remains on the principles of modernity. We are in the world of presentation rather than in that of representation.

Representation belongs to modernity. The educatinal institution refers to the world of representation, to the world of clarity and to the principle of sufficient reason. "The representation shows that it is a mechanism of deception, we do not need to presuppose while dealing with the essence of things." [20]

We must be attentive to the "métanoïaque" attitude evoked by Patrick Tacussel, which refers to a holistic process. This emphasizes the concepts but also the representations based on abstraction but not on empathy, metaphor, intuition, analogy, and emphasizes the feeling, the organic and the imagination. "A sociology of métanoïaque, forms of collective sensibility that activate social mentality beside or above reasonable behavior, consistent habits and appearance, is necessarily guided by attention to detail." [21]

The thematic context represents the intangible aspect what is to say the imagination and emotional aspects. It is not only economic power is the strength in today's world, it is also the power of the intangible.

The emphasis is placed on the importance of mental and spiritual atmosphere. Acording to Michel Maffesoli, an atmosphere must take shape, something cannot exist in time if it does not crystallize. This may exist, and this is to conceptualize the process of "formism". Shapes are the founders of the social bond. They are both rooted in our minds and in the imagination, such as the archetypal forms. Postmodernity refers to premodern tradition.

\section{Democratization of the school life: dissonance between faculty and student's expectations}

The macrocosm of postmodern society should permanently interact with the microcosm of the educational system.

There must be consistency and harmony. However, that is not the case. There are profound dissonance between the postmodern social atmosphere and the education system.

In this context and in the light of the "Democracy at School" analysis provided by the French specialist of educational issues Anne Barrere, this can be illustrated by the example of 'rights against obligations'.

\section{The utopia of the dialectic 'rights against obligations}

In the official language of the teacher's community it is often said that: "Yes, students have 
rights, but we must not forget that they have duties." [22]

This suggests that the educational institution has advocated various forms of citizenship at school, the implementation of certain rights, in order to establish rules and standarts for appropriate climate at school. It is to say a form of "post-conventional" authority. If rights are given to students, it would be easier to make them accept the duties. It relates to establishing a form of implicit exchange. This is indicated by the emergence of practices of contracts between the institution and the students.

According to A. Barrere, this is a form of institution utopia that does learning rights would encourage students in following the rules.

We believe that students need a structure within which they recognize a concern for their well-being amongst their peers, their parents and their teachers together with the support which they offer; a structure which can give them the necessary knowledge and confidence to make good choices.

\section{References}

[1] Anne Barrère, Debate on democracy at school, Université Paris 5 Descartes Sorbonne, June $19^{\text {th }} 2013$.

[2] Barrere A., "Transcription response and school work", Internet ref: DAFOR / MD / Transcription response $\mathrm{AB}$ / University of Lille III, Created on 12/04/09.

[3] Bourdieu P., Wacquant L., Réponses , Paris , Editions du Seuil , coll. Free Review, 1992.

[4] D. Baillet., "Language suburbs, between cultural impoverishment and social exclusion", Journal H \& M No. 1231, No. 29, May-June 2001.

[5] Duru- Bellat Mr. Van Zanten and A., Sociology School, Paris, Armand Colin, 1999.

[6] Friedrich Nietzsche, La naissance de la tragédie, Paris, Gallimard, Coll. Folio, 1989.

[7] Goudaillier J.-P., How do you chats - Dictionary of Contemporary French cities, Paris Maisonneuve \& Larose, 2001.

[9] Krichewsky M., Educational Transitional : The experiment itself together to develop "soft skills" , University Paris 8, March 2009.

[10] Mayes, C. Jung and education, Elements of Archetypal Pedagogy, Rowman \& Littlefield Education, Oxford, 2005.

[11] Mayes Clifford, Teaching Mysteries. Foundations of Spiritual Pedagogy, Oxford, University Press of America, Inc, 2005.
[12] Mayes, C. Inside Education, Depth Psychology in Teachin and Learning, Atwood Publishing, Madison, WI, 2007.

[13] Maffesoli M., Ordinary Knowledge. Precise understanding of Sociology, Paris, 1985.

[14] Maffesoli M., Conference, "Modern nomadic tribes and techno." Cosne, 20/11/1998.

[15] Maffesoli M., The hollow appearances - For an ethics of aesthetics, Paris, La Table Ronde, 2007.

[16] Maffesoli M., Weather returns - Elementary Forms of postmodernity, Paris, DDB, 2010.

Maffesoli, M. (2003) Notes sur la postmodernité. Paris: Editions du Félin/Institut du monde arabe.

[17] Michael Tyldesley, An Interview with Michel Maffesoli, Theory Culture Society journal, Postmodernity, Aesthetics and Tribalism: Published online 7 April 2013 by SAGE: http://www.sagepublications.com.

[18] Michaela Fiserova, "Interview with Mr. Maffesoli", Sense Review, 19/02/2006, published online (URL: http://www.jeunes-vocations.catholique.fr/download/117331-0/entretien-avec-le-sociologue-michel-maffesolidoc.doc).

[19] Perrenoud P., The production of academic excellence: curriculum to assessment practices, Geneva, Droz, 1984.

[20] Piaget J., Psychology and Epistemology, Paris, Gonthiers Denoël al. Mediations, 1970. 